\title{
HISTOPATHOLOGICAL AND \\ IMMUNOHISTOCHEMICAL CHARACTERISTICS OF 22 CASES OF MALE BREAST CANCER
}

Kauana C. S.Nascimento', Délio M. Conde², Sebastião A. Pinto³

'Serviço de Mastologia, Hospital Geral de Goiânia - Goiânia (GO), Brazil.

²Departamento de Ginecologia e Obstetrícia, Universidade Federal de Goiás - Goiânia (GO), Brazil.

${ }^{3}$ Serviço de Patologia, Instituto Goiano de Oncologia e Hematologia - Goiânia (GO), Brazil.

Introduction: Male breast cancer is unusual. Due to this low frequency, little information of histopathological characteristics are known. Objectives: Describe the histopathological and immunohistochemical characteristics of male breast cancer. Methodology: A retrospective study was conducted with the evaluation of 22 cases of male breast cancer. We investigated the age, histological type, histological grade, lymphocytic infiltrate, lymphovascular and neural invasion, estrogen receptor (ER), progesterone (PR), androgen receptor (AR), HER2, Ki67, CK14, BCL2, and p53. The absolute and relative frequencies, mean \pm standard deviation, and median were calculated. Results: The mean age was $62.4 \pm 11.9$ years (range $=42-90$ years). There were 21 cases of infiltrating mammary carcinoma and 1 of carcinoma in situ. The most common was non-special type infiltrating carcinoma (13 cases). The majority, 15 cases, presented histological grade 2. Lymphocytic infiltrate was considered scarce in 11 cases (50\%). Lymphovascular invasion was present in 4 cases and neural invasion in 3 cases. The frequency of hormone receptor positivity was: $\mathrm{RE}=20$ cases (90.9\%), $\mathrm{PR}=17$ cases (77.3\%), AR=9 cases (40.9\%). The other markers presented the following distribution of positivity: HER2 $=5$ cases (22.7\%), p53=19 cases (86.4\%), BCL2 $=20$ cases (90.9\%). CK14 was negative in all cases. The Ki67 index presented a mean of $17.7 \pm 19.7 \%$ and a median of 10\%. Luminal A corresponded to 11 cases (50\%). Conclusion: Most tumors were positive hormonal receptor. AR expression was common. The luminal A was the most frequent molecular subtype. 